\title{
Frustrated Layered Self-assembly Induced Superlattice
}

\section{from Two-Dimensional Nanosheets}

Huanjun Lu, ${ }^{1 \dagger}$ Xiaoyan Zhang, ${ }^{2 \dagger}$ Tsuneaki Sakurai, ${ }^{3}$ Xiaohong Li, ${ }^{1}$ Yingfeng Tu, ${ }^{1 *}$ Jun Guo, ${ }^{4}$ Shu Seki, ${ }^{3}$ Christopher Y. Li,${ }^{5}$ Goran Ungar $6,7 *$ and Stephen Z.D. Cheng ${ }^{8,9}$

${ }^{1}$ Jiangsu Key Laboratory of Advanced Functional Polymer Design and Application, College of Chemistry, Chemical Engineering and Materials Science, Soochow University, Suzhou 215123, China

${ }^{2}$ College of Materials Science and Engineering, Qingdao University, Qingdao 266071, China

${ }^{3}$ Department of Molecular Engineering, Graduate School of Engineering, Kyoto University, Nishikyo-ku, Kyoto 615-8510, Japan

${ }^{4}$ Testing and Analysis Center, Soochow University, Suzhou 215123, China

${ }^{5}$ Department of Materials Science and Engineering, Drexel University, Philadelphia, PA 19104, United States

${ }^{6}$ State Key Laboratory for Mechanical Behaviour of Materials, Shanxi International Research Center for Soft Materials, Xi'an Jiaotong University, Xi'an 710049, China

${ }^{7}$ Department of Materials Science and Engineering, University of Sheffield, Sheffield S1 3JD, United Kingdom

${ }^{8}$ South China Advanced Institute for Soft Matter Science and Technology, School of Molecular Science and Engineering, South China University of Technology, Guangzhou 510640, China

${ }^{9}$ Department of Polymer Science, College of Polymer Science and Polymer Engineering, University of Akron, Akron, $\mathrm{OH} 44325$, United States

$\dagger$ These authors contributed equally.

*Corresponding authors. Email: tuyingfeng@suda.edu.cn; g.ungar@sheffield.ac.uk

\section{Table of Contents}

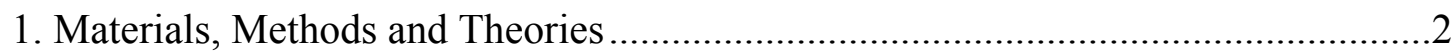

2. Synthetic procedures and characterization data .................................................6

3. Structure of the LQ phase, calculations for the SL phase and electron-transport

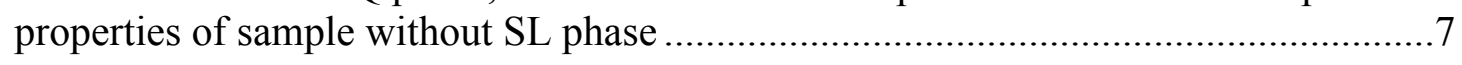

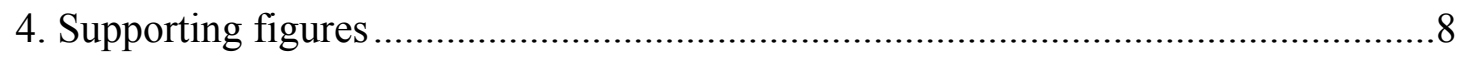

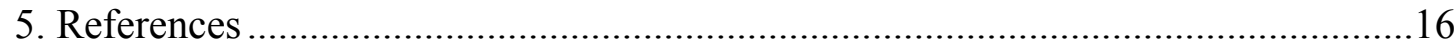




\section{Materials, Methods and Theories}

\section{Reagents}

1-Bromoheptane (99\%), p-toluenesulfonic acid (PTSA, $99 \%$ ) (all from J\&K Chemical), methyl 3,4,5-trihydroxybenzoate (98 \%), 1,8-octanediol (98+ \%), 4(dimethylamino)pyridine (DMAP, $99 \%$ ), N,N-diisopropylcarbodiimide (DIPC, $99 \%$ ), 1,2-dichlorobenzene (99 \%) (all from Alfa Aesar), trifluoroacetic acid (chemically pure), $N, N$-dimethylformamide (DMF, analytical reagent) (all from Sinopharm Chemical Reagent Co., Ltd, China) were used as received. [60]Fullerene (99.9 \%) was purchased from Yongxin Technology Co., Ltd (Henan, China). [60]Fullerenoacetic acid was synthesized as reference. ${ }^{1,2}$ All other chemicals were commercially available and were used as received.

\section{Instruments and Methods}

NMR spectra were obtained on an Agilent Direct-Drive П $600 \mathrm{MHz}$ NMR spectrometer $\left(600 \mathrm{MHz}{ }^{1} \mathrm{H}\right.$ and $150 \mathrm{MHz}{ }^{13} \mathrm{C}$ Larmor frequency). The chemical shifts ( $\delta$ values) were measured in parts per million (ppm) down-field from tetramethylsilane (TMS) as an internal reference. MALDI-TOF mass spectra were acquired on a GCT-Primier mass spectrometer. Trans-2-[3-(4-tert-butylphenyl)-2methyl-2-propenylidene]malononitrile (DCTB) was served as matrix and was prepared in $\mathrm{CHCl}_{3}$ at a concentration of $20 \mathrm{mg} / \mathrm{mL}$. Sodium iodide (NaI) served as cationizing agent and was prepared in methanol at a concentration of $10 \mathrm{mg} / \mathrm{mL}$.

TGA was carried out on a Perkin-Elmer Pyris 6 with a heating rate of $10{ }^{\circ} \mathrm{C} / \mathrm{min}$ in nitrogen atmosphere.

DSC measurements were carried out on a TA Q 200 instrument with nitrogen as the purge gas. Aluminum sample pans were used.

POM observations were carried out on a polarizing microscope (Olympus Corporation, BX51-P) which was coupled with a computer-controlled video camera. A dual hot stage (Linkam THMS600) was used for controlling the temperature.

SAXS experiments were carried out on an X-ray scattering instrument (SAXSess $\mathrm{mc}^{2}$, Anton Paar) equipped with line collimation and a $2200 \mathrm{~W}$ sealed-tube X-ray generator $(\mathrm{Cu}-\mathrm{K} \alpha, \lambda=0.154 \mathrm{~nm})$. Powder samples were wrapped in aluminum foil for SAXS experiments. The sample was kept under vacuum during irradiation. An imaging plate was used to record the scattering pattern. Silver behenate was used as the calibration standard.

TEM samples for flat-on lamellar morphology were prepared by drop casting $0.002 \%$ (wt) $\mathrm{CH}_{2} \mathrm{Cl}_{2}$ solution on carbon-coated mica. After evaporation of residual solvent, the samples were thermally treated by heating up to $170{ }^{\circ} \mathrm{C}$ followed by slow cooling to $100{ }^{\circ} \mathrm{C}$ at the rate of $1{ }^{\circ} \mathrm{C} /$ min under nitrogen. The sample was sheared by a spatula at $100{ }^{\circ} \mathrm{C}$ then quenched immediately to room temperature. The sample was transferred to TEM grids by floating off the carbon film with the sample on the surface of distilled water, and then picked up by regular copper grids (300 mesh). The TEM images of the edge-on lamellar morphology were observed from $50 \mathrm{~nm}$-thick 
sections microtomed by a Leica UC7-FC7 ultramicrotome at $-50{ }^{\circ} \mathrm{C}$. The exfoliated nanosheets were prepared by dispersing the annealed sample in $n$-hexane. The annealing temperature was $70{ }^{\circ} \mathrm{C}$. The dispersion was transferred to a copper grid for TEM investigation. High-resolution STEM was performed on a FEI T G2 F20 S/TEM at $200 \mathrm{kV}$ using a high-angle annular dark-field (HAADF) detector. Fourier filtering of the STEM image was carried out with the FFTW implementation. ${ }^{3}$ The exfoliated nanosheets were also transferred to silicon wafer for AFM investigation. AFM imaging was carried out on a MultiMode 8 Atomic Force Microscope (Bruker Veeco) in PeakForce QNM mode with $\mathrm{Si}_{3} \mathrm{~N}_{4}$ cantilever (spring constant: $0.35 \mathrm{~N} / \mathrm{m}$, resonance frequency: $50-80 \mathrm{kHz}$ ).

FP-TRMC was performed at room temperature in air. Nanosecond pulses from a Nd:YAG laser from Spectra-Physics INDI-HG (full width at half maximum $(\phi \Sigma \mu)$ of 5-8 ns) was used as an excitation light source. Films, on quartz plates, prepared from $\mathrm{C}_{7}-\mathrm{C}_{8}-\mathrm{C}_{60}$ in the different LC phases were exposed to the third harmonic (355 nm) pulses. $\mathrm{C}_{7}-\mathrm{C}_{8}-\mathrm{C}_{60}$ film in the high-temperature LQ phase was prepared immediately before the experiment by raising the temperature up to melting, and then cooling to room temperature. The SL phase film was obtained by annealing the above sample for 2 weeks at room temperature. These phases are confirmed by the SAXS experiments (Figure S16). The laser power density was set at $10 \mathrm{~mW}\left(9.1 \times 10^{15}\right.$ photons $\left.\mathrm{cm}^{-2}\right)$. The microwave frequency and power were set at approximately $9.1 \mathrm{GHz}$ and $3 \mathrm{~mW}$, respectively, and the TRMC signal was evolved in a diode (rise time $<1 \mathrm{~ns}$ ), and the output signal was fed into a Tektronix TDS 3032B digital oscilloscope.

\section{Theories}

\section{(1) FP-TRMC}

Reflected power change ratio $\left(\Delta P_{\mathrm{r}} / P_{\mathrm{r}}\right)$ of microwave from the cavity in FP-TRMC apparatus is in relation with the total loss $(\Delta(1 / Q))$ of microwave by the photoinduced transient species in the cavity as follows: ${ }^{4}$

$$
\frac{\Delta P_{\mathrm{r}}}{P_{\mathrm{r}}}=\frac{\left(\frac{1}{Q}\right)}{\left(\frac{\Delta \omega}{\omega_{0}}\right)^{2}+\left(\frac{1}{2 Q}\right)^{2}} \Delta\left(\frac{1}{Q}\right)
$$

where $\omega_{0}$ and $\Delta \omega$ are the resonant frequency of $9.1 \mathrm{GHz}$ and its shift by the photoinduced transient species. The loss and the frequency shift of the microwave are expressed as a function of complex conductivity $\left(\Delta \sigma_{\mathrm{r}}+i \Delta \sigma_{\mathrm{i}}\right)$ of the transient species by:

$$
\Delta\left(\frac{1}{Q}\right)-i \frac{2 \Delta \omega}{\omega_{0}}=F\left(\Delta \sigma_{\mathrm{r}}+i \Delta \sigma_{\mathrm{i}}\right)
$$

where $F$ is a calibration factor derived from the measurements of total loss of microwave in the cavity loaded with materials with well-known conductivity values. The value of $\Delta P_{\mathrm{r}} / P_{\mathrm{r}}$ is proportional to the sum of the mobilities $(\Sigma \mu)$ of charged species in case of negligibly small $\Delta \omega$ :

$$
\Delta \sigma_{\mathrm{r}}=N \phi \sum \mu=\mathrm{A} \frac{\Delta P_{\mathrm{R}}}{P_{\mathrm{R}}}
$$


where $N, \phi$, and $\mathrm{A}$ are the number of absorbed photons, photo-carrier separation quantum yield, and a sensitivity factor (constant), respectively. Details in the sensitivity factor A are described elsewhere. ${ }^{5}$

\section{(2) Electron density reconstruction}

Along the layer normal

Since the electron density profile of a smectic liquid crystal is a periodic function, it can be represented as a Fourier series. Also, as smectic structure has a centre of symmetry, the profile is an even function. Hence the electron density along the layer normal could be reconstructed on the basis of the general formula:

$$
\rho(z)=\sum_{n=0}^{\infty} F_{n} \cos \left(\frac{2 \pi n z}{L}\right)
$$

here $F_{n}$ is the structure factor of the $n$th diffraction peak of the smectic phase. $L$ is the layer thickness.

We can only aim at reconstructing the electron density with limited diffraction peaks, thus

$$
\rho(z)=\sum_{n=1}^{N} F_{n} \cos \left(\frac{2 \pi n z}{L}\right)
$$

The structure factor $F_{n}$ has a relationship with the experimentally observed diffraction intensity $I_{n}$, which is:

$$
I_{n}=\mathrm{K} \cdot F_{n} \cdot F_{n}{ }^{*}=\mathrm{K} \cdot\left|F_{n}\right|^{2}
$$

here $\mathrm{K}$ is a constant related to the sample volume, incident beam intensity etc. In this paper we are only interested in the relative electron densities, hence this constant is simply taken to be 1 . As the observed diffraction intensity $I_{n}$ is only related to the amplitude of the structure factor $\left|F_{n}\right|$, the information about the phase of $F_{n}, \phi_{n}$, cannot be determined directly from experiment. However, the problem is significantly simplified in a centro-symmetric smectic structure, where the phase angle $\phi_{n}$ of a given $n$th reflection is limited to 0 or $\pi$. In this case, the phase problem reduces to the choice of sign of $F_{n}$.

Table S1. Experimental $d$-spacings, relative integrated intensities, and phases of the SL phase in $\mathrm{C}_{7}-\mathrm{C}_{8}-\mathrm{C}_{60}$ used in the reconstruction of $\rho(z)$; all intensity values are Lorentz and multiplicity corrected.

\begin{tabular}{cccc}
\hline$(h k l)$ & $d_{\text {obs. }}-$ spacing $(\mathrm{nm})$ & $\begin{array}{c}\text { intensity } \\
\text { (Lorentz corrected) }\end{array}$ & phase \\
\hline$(001)$ & 10.08 & 100 & $\pi$ \\
$(002)$ & 4.99 & 56.2 & $\pi$ \\
$(003)$ & 3.34 & 11.8 & $\pi$ \\
$(004)$ & 2.47 & 41.5 & $\pi$ \\
$(005)$ & 2.00 & 2.13 & $\pi$ \\
$(006)$ & 1.68 & 78.9 & $\pi$ \\
\hline
\end{tabular}


Table S2. Experimental $d$-spacings, relative integrated intensities, and phases of the LQ phase in $\mathrm{C}_{7}-\mathrm{C}_{8}-\mathrm{C}_{60}$ used in the reconstruction of $\rho(z)$; all intensity values are Lorentz and multiplicity corrected.

\begin{tabular}{cccc}
\hline$(h k l)$ & $d_{\text {obs. }}$-spacing $(\mathrm{nm})$ & $\begin{array}{c}\text { intensity } \\
\text { (Lorentz corrected) }\end{array}$ & phase \\
\hline$(001)$ & 5.71 & 100 & $\pi$ \\
$(002)$ & 2.85 & 1.22 & $\pi$ \\
$(004)$ & 1.41 & 11.6 & $\pi$ \\
\hline
\end{tabular}

Within the layer plane

Two-dimensional electron density maps could be reconstructed on the basis of the general formula:

$$
\rho(x y)=\sum_{h k} F(h k) \exp [i 2 \pi(h x+k y)]
$$

here $F(h k)$ is the structure factor of a diffraction peak with index $(h k)$. The experimentally observed diffraction intensity

$$
I(h k)=K \cdot F(h k) \cdot F^{*}(h k)=K \cdot|F(h k)|^{2}
$$

here $\mathrm{K}$ is a constant related to the sample volume, incident beam intensity etc. In this paper we are only interested in the relative electron densities, hence this constant is simply taken to be 1 . Thus the electron density is

$$
\rho(x y)=\sum_{h k} \operatorname{sqrt}[I(h k)] \exp \left[i 2 \pi(h x+k y)+\varphi_{h k}\right]
$$

here $\phi_{h k}$ is the phase angle of the $h k$ Bragg reflection.

As the observed diffraction intensity $I(h k)$ is only related to the amplitude of the structure factor $|F(h k)|$, the information about the phase of $F(h k), \phi_{h k}$, cannot be determined directly from experiment. However, the problem is significantly simplified with most space group symmetries, where the phase angle $\phi_{h k}$ of a given $(h k)$ reflection has limited choices. In this work, the structure of the fullerene balls has a 2D square $p 4 \mathrm{~mm}$ symmetry, which is centrosymmetric. Thus the phase angle $\phi_{h k}$ is limited to 0 or $\pi$.

Table S3. Experimental $d$-spacings, relative integrated intensities, and phases of the SL phase used in the reconstruction of $\rho(x y)$; all intensity values are Lorentz and multiplicity corrected.

\begin{tabular}{cccc}
\hline$(h k)$ & $d_{\text {obs. }}$-spacing $(\mathrm{nm})$ & $\begin{array}{c}\text { intensity } \\
\text { (Lorentz corrected) }\end{array}$ & phase \\
\hline$(10)$ & 1.01 & 100 & 0 \\
$(11)$ & 0.712 & 37.2 & $\pi$ \\
$(20)$ & 0.509 & 85.2 & $\pi$ \\
\hline \multicolumn{5}{l}{} \\
\hline
\end{tabular}

Table S4. Experimental $d$-spacings, relative integrated intensities, and phases of the LQ phase used in the reconstruction of $\rho(x y)$; all intensity values are Lorentz and multiplicity corrected.

\begin{tabular}{cccc}
\hline$(h k)$ & $d_{\text {obs. }}-$ spacing $(\mathrm{nm})$ & $\begin{array}{c}\text { intensity } \\
\text { (Lorentz corrected) }\end{array}$ & phase \\
\hline$(10)$ & 1.01 & 2.72 & 0 \\
$(11)$ & 0.715 & 4.31 & $\pi$ \\
$(20)$ & 0.504 & 100 & $\pi$ \\
\hline
\end{tabular}




\section{(3) Calculation of fitting model for the reconstruction of electron density profile}

For an 1D density function $\rho(z)$ with periodicity $a$, the structure factor of the $n$th order diffraction peak

$$
F(n)=\int_{-a / 2}^{a / 2} \rho(z) \exp \left(\frac{i 2 \pi n z}{a}\right) d z
$$

If the function is centrosymmetric, that is $\rho(z)=\rho(-z), F(n)$ is always real. Then

$$
F(n)=\int_{-a / 2}^{a / 2} \rho(z) \cos \left(\frac{2 \pi n z}{a}\right) d z
$$

A trapezoidal model (Figure S10) is used to fit the experimental data. From the model, $\rho^{\text {trap }}(z)$ can be rewritten as:

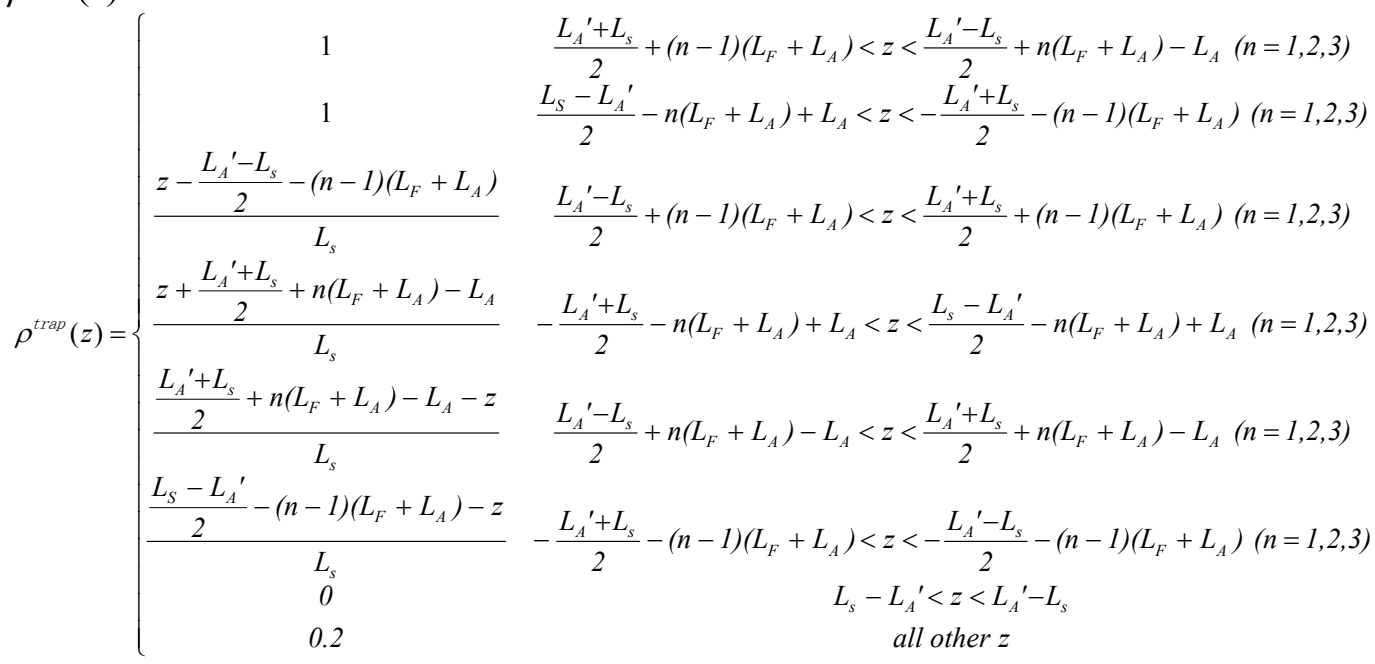

where $L_{F}$ is the layer thickness of the fullerene spheres; $L_{A}$ is the layer thickness of the alkyl cones within one period; $L_{A}$ ' is the layer thickness of the alkyl cones between the long-period lamellae; $L_{S}$ is the thickness of a thin electron density transition layer. The structure factor can be calculated by integration of $\rho^{\operatorname{trap}}(z)$.

The fitting parameters are listed below:

Table S5. Fitting parameters for the electron density profile of the SL phase

\begin{tabular}{cccc}
\hline$L_{F}(\mathrm{~nm})$ & $L_{A}(\mathrm{~nm})$ & $L_{A}{ }^{\prime}(\mathrm{nm})$ & $L_{S}(\mathrm{~nm})$ \\
\hline 1.0 & 0.6 & 1.2 & 0.4 \\
\hline
\end{tabular}

\section{Synthetic procedures and characterization data}

$\mathrm{C}_{7}-\mathrm{C}_{8}-\mathrm{C}_{60}$ was synthesized as same as the procedure reported previously. ${ }^{6}$

$\mathrm{C}_{7}-\mathrm{C}_{8}-\mathrm{C}_{60}:{ }^{1} \mathrm{H}$ NMR $\left(600 \mathrm{MHz}, \mathrm{CDCl}_{3}\right): \delta 0.89(\mathrm{t}, 9 \mathrm{H}), 1.20-1.61(\mathrm{~m}, 32 \mathrm{H}), 1.68-1.94$ $(\mathrm{m}, 10 \mathrm{H}), 4.01(\mathrm{t}, 6 \mathrm{H}), 4.29(\mathrm{t}, 2 \mathrm{H}), 4.47(\mathrm{t}, 2 \mathrm{H}), 4.79(\mathrm{~s}, 1 \mathrm{H}), 7.25(\mathrm{~s}, 2 \mathrm{H}) .{ }^{13} \mathrm{C} \mathrm{NMR}$ $\left(150 \mathrm{MHz}, \mathrm{CDCl}_{3}\right): \delta 14.12,22.63,22.67,25.94,26.00,26.07,28.69,28.77,29.07$, $29.20,29.21,29.24,29.34,29.33,31.83,31.91,31.94,39.13,65.03,66.52,73.49$, $76.81,77.02,77.23,108.09,125.02,136.35,140.46,140.89,141.10,142.04,142.18$, $142.39,142.76,142.94,143.07,143.24,143.70,143.92,144.38,144.56,144.64$, $145.04,145.06,145.15,145.18,145.23,145.55,145.80,148.25,152.78,166.40$, 166.46. MALDI-TOF, Calc. for $\mathrm{C}_{98} \mathrm{H}_{64} \mathrm{O}_{7}:(\mathrm{M})^{+}$1352.465. Found: 1352.971 . 


\section{Structure of the LQ phase, calculations for the SL phase and electron-transport properties of sample without SL phase}

\section{Structure of the high-temperature LQ phase}

The high-temperature mesophase (LQ phase, lamellar LC with quadruple-layer fullerenes) is formed at the temperature range between $130{ }^{\circ} \mathrm{C}$ and $160{ }^{\circ} \mathrm{C}$ upon heating. The SAXS result at $144^{\circ} \mathrm{C}$ shows two sets of diffraction peaks (Figure S12). The (001) peak of the lamellar LC structure is observed at $q=1.10 \mathrm{~nm}^{-1}$ corresponding to a layer thickness of $5.71 \mathrm{~nm}$, with another set ascribed to the (100'), (110') and (200') peaks from crystalline 2D square lattice at the same position as those of the SL phase.

We have previously reported that the fullerene block molecule analogues $\left(\mathrm{C}_{6}-\mathrm{C}_{8^{-}}\right.$ $\mathrm{C}_{60}$ and $\mathrm{C}_{8}-\mathrm{C}_{8}-\mathrm{C}_{60}$ ) of sample $\mathrm{C}_{7}-\mathrm{C}_{8}-\mathrm{C}_{60}$ form crystalline $2 \mathrm{D}$ nanolayers constructed lamellar supramolecular LCs with quadruple-layer stacking of fullerenes at high temperatures (Figure S13). ${ }^{7}$ The high temperature phase for $\mathrm{C}_{7}-\mathrm{C}_{8}-\mathrm{C}_{60}$ can be easily identified as quadruple-layer stacking of fullerenes due to the similar diffraction patterns and the reconstructed electron density profile projected on the crystalline plane and along the layer normal (Figure S13c and S14), together with the observed lamellar periodicity $(5.71 \mathrm{~nm})$ fitting well between them $\left(5.51 \mathrm{~nm}\right.$ for $\mathrm{C}_{6}-\mathrm{C}_{8}-\mathrm{C}_{60}$ and $5.81 \mathrm{~nm}$ for $\left.\mathrm{C}_{8}-\mathrm{C}_{8}-\mathrm{C}_{60}\right)$. This is also confirmed by the transmission electron microscopy (TEM) observation of a well-ordered lamellar structure with the average thickness about $5 \mathrm{~nm}$ (Figure S15).

The phase transition takes place between the SL phase and the LQ phase with quadruple-layer stacking of fullerenes might be caused by the expanding volume of the alkyl cones with the increase of temperature. To satisfy the molecular packing of the SL phase, the volume ratio between the fullerene spheres and the alkyl cones is quite restrict. On heating, the superlattice structure is broken as the volume of the alkyl cones extend more than that of the fullerene spheres. Consequently, the LQ phase with quadruple-layer of fullerenes in the middle, terminal alkyl chains at both sides and flexible spacers penetrating out from the holes between the tetragonally packed fullerenes is formed as its analogues.

\section{Calculations for the molecular packing in the SL phase}

According to the STEM image, there are six bright stripes, five narrow dark stripes and one broad dark stripe among one superlattice. The thickness of the lamellar superlattice is $10.08 \mathrm{~nm}$ from SAXS results. Considering the bright stripe is consist of $\mathrm{C}_{60} \mathrm{~s}$, which has a specific diameter of $1 \mathrm{~nm}$, the thickness of one narrow dark stripe is calculated as $0.583 \mathrm{~nm}$ if the thickness of the broad dark stripe is suspected as twice as that of the narrow one. The occupied volume of the groups connected to $\mathrm{C}_{60}$ (the cone) was calculated using Materials Studio by Connolly surface method. In this method, a sphere with Connolly radius (Connolly probe) rolled over the molecule to generate a smooth contour (Connolly surface) between the 
Connolly probe and the scaled van der Waals (vdW) radii of the molecule. ${ }^{8,9}$ Then the volume inside Connolly surface was computed with an error of about $0.01 \% .{ }^{10}$ The grid interval was $0.1500 \AA$. vdW scale factor was 1.0000 . Connolly radius was 1.0000 $\AA$. Under the above conditions, the occupied volume of the cone was calculated to be $0.707 \mathrm{~nm}^{3}$. Thus, a cone needs roughly $1.21 \mathrm{~nm}^{2}$ surface area.

At high temperatures, the thermal expansion coefficient of the cones was calculated using the following equation: ${ }^{11,12}$

$$
\alpha=1.21 \times 10^{-3}+1.37 \times 10^{-6} T+1.12 \times 10^{-8} T^{2}+1.16 \times 10^{-10} T^{3} \quad K^{-1}
$$

where $T$ is temperature. Thus the occupied volume of the cone at $130{ }^{\circ} \mathrm{C}$ was extrapolated to be $0.822 \mathrm{~nm}^{3}$. Considering the layer thickness was $0.583 \mathrm{~nm}$, the needed surface area would be $1.41 \mathrm{~nm}^{2}$, which was far beyond the area provided by one fullerene $\left(1.00 \mathrm{~nm}^{2}\right)$ and could not be resolved by flipping the molecules.

\section{Electron-transport properties of sample without SL phase}

The FP-TRMC measurement of $\mathrm{C}_{7}-\mathrm{C}_{8}-\mathrm{C}_{60}$ in SL phase was carried out after annealing at room temperature for two weeks. As a comparison, the charge mobility of compound $\mathrm{C}_{14}-\mathrm{C}_{8}-\mathrm{C}_{60}$ which only forms $\mathrm{LC}$ phase with triple-layer stacking of fullerenes ${ }^{6}$ was tested with the same sample preparation procedures. As showed in Figure S17, there is no significant improvement of charge mobility after two-weeks annealing. This result evidences that the increase of charge mobility of $\mathrm{C}_{7}-\mathrm{C}_{8}-\mathrm{C}_{60}$ is caused by the formation of SL phase rather than the long-time annealing.

\section{Supporting figures}

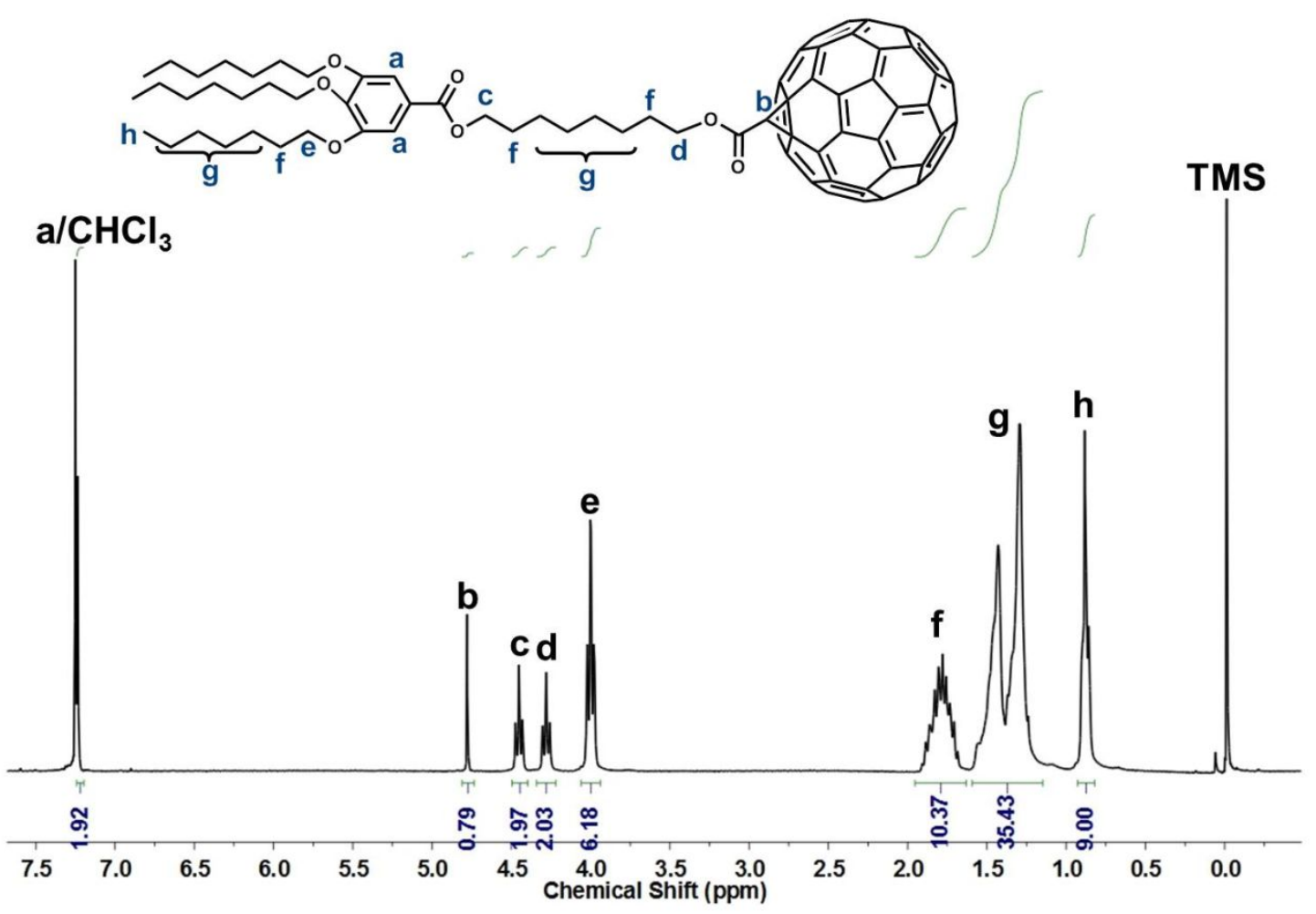

Figure S1. ${ }^{1} \mathrm{H}$ NMR spectrum of $\mathrm{C}_{7}-\mathrm{C}_{8}-\mathrm{C}_{60}$. 


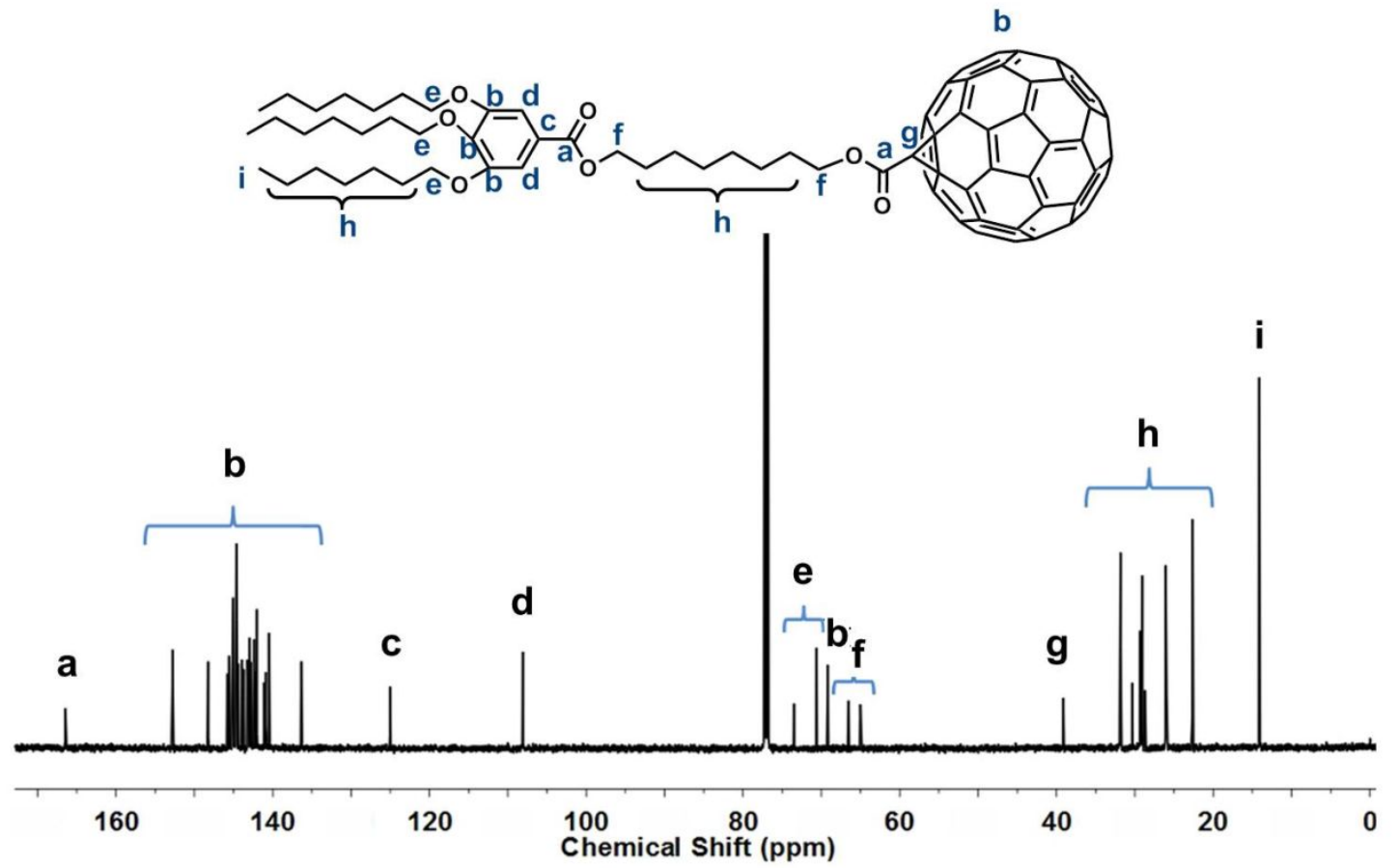

Figure S2. ${ }^{13} \mathrm{C}$ NMR spectrum of $\mathrm{C}_{7}-\mathrm{C}_{8}-\mathrm{C}_{60}$.
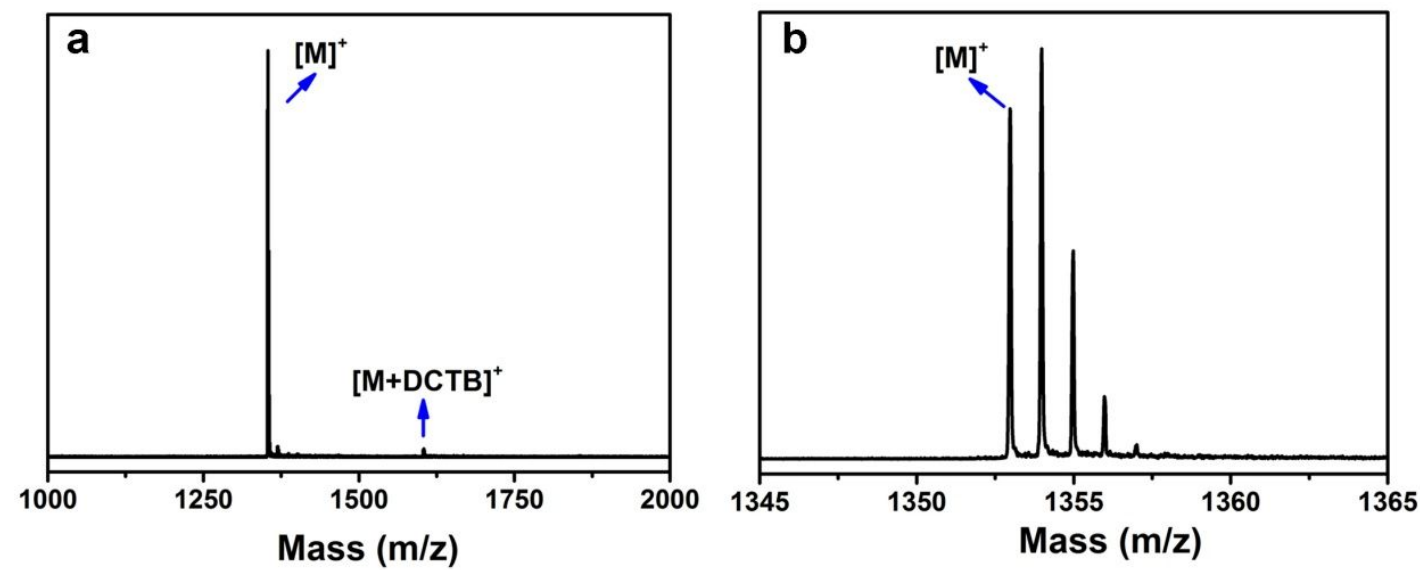

Figure S3. MALDI-TOF mass spectra of $\mathrm{C}_{7}-\mathrm{C}_{8}-\mathrm{C}_{60}$. (a) The overview of the spectrum. (b) The zoom-in view of the spectrum. 


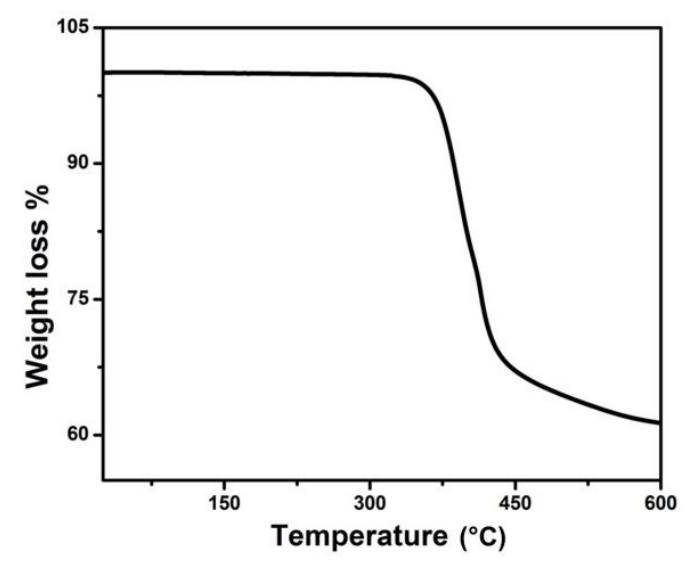

Figure S4. TGA curve of $\mathrm{C}_{7}-\mathrm{C}_{8}-\mathrm{C}_{60}$. Rate: $10{ }^{\circ} \mathrm{C} / \mathrm{min}, \mathrm{N}_{2}$.
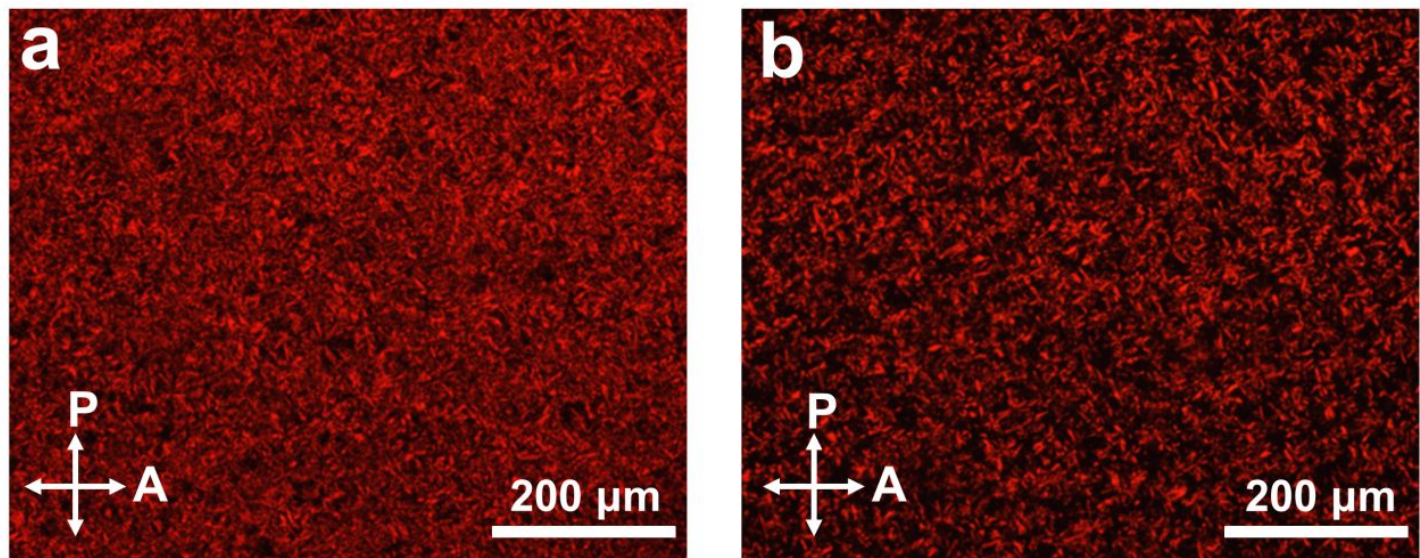

Figure S5. Polarized optical micrographs of $\mathrm{C}_{7}-\mathrm{C}_{8}-\mathrm{C}_{60}$ at $90{ }^{\circ} \mathrm{C}$ (a) and $150{ }^{\circ} \mathrm{C}$ (b).

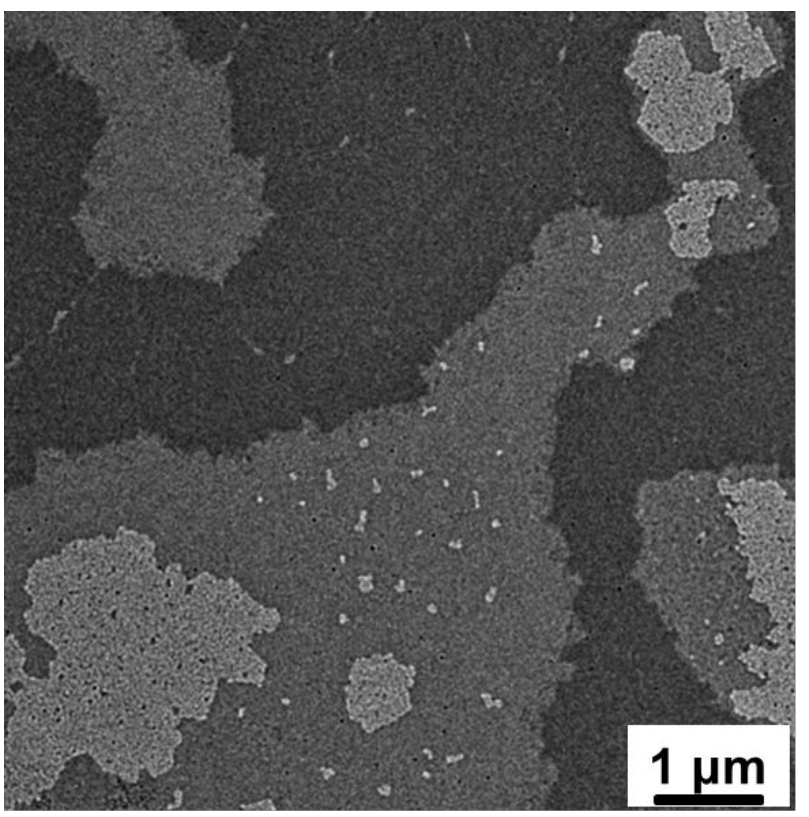

Figure S6. TEM image of the nanosheets formed by $\mathrm{C}_{7}-\mathrm{C}_{8}-\mathrm{C}_{60}$ at $80{ }^{\circ} \mathrm{C}$. 

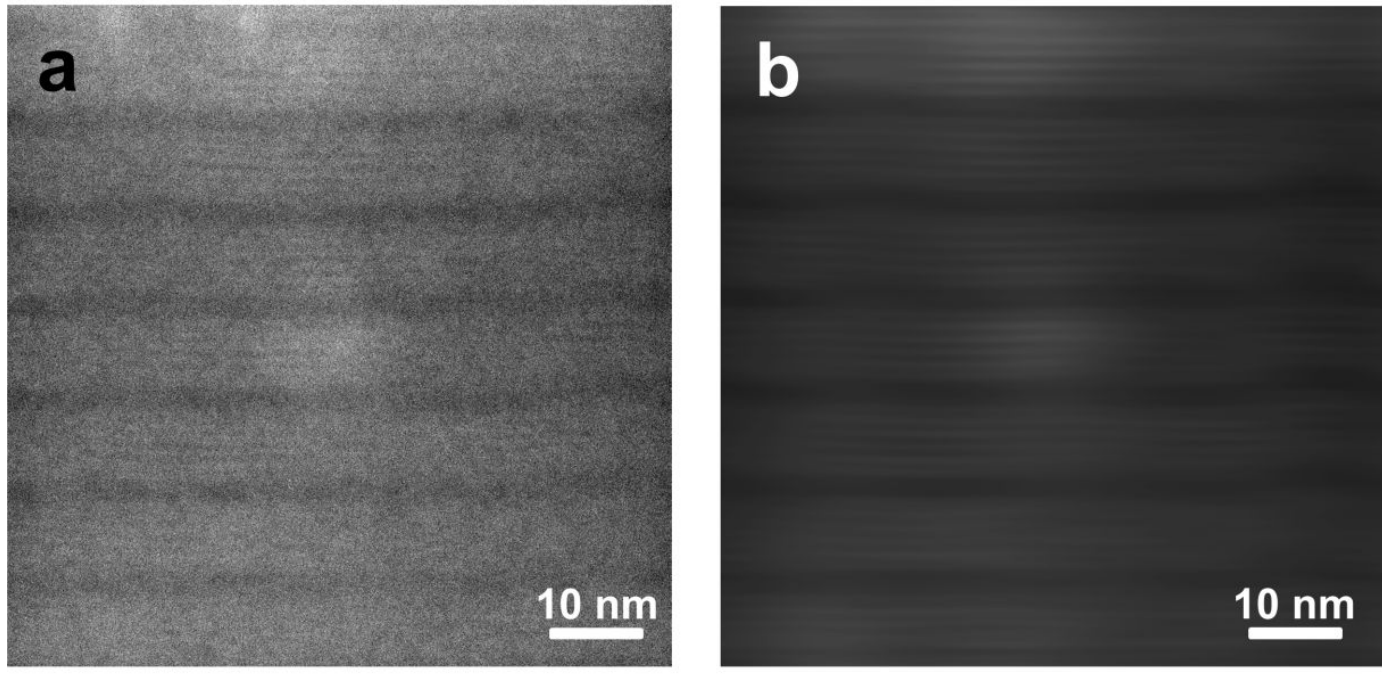

Figure S7. (a) STEM image of the microtomed sample in the SL phase. (b) Fourier filtering of the image shown in (b) revealed a clear view of the layers-in-lamella structure.

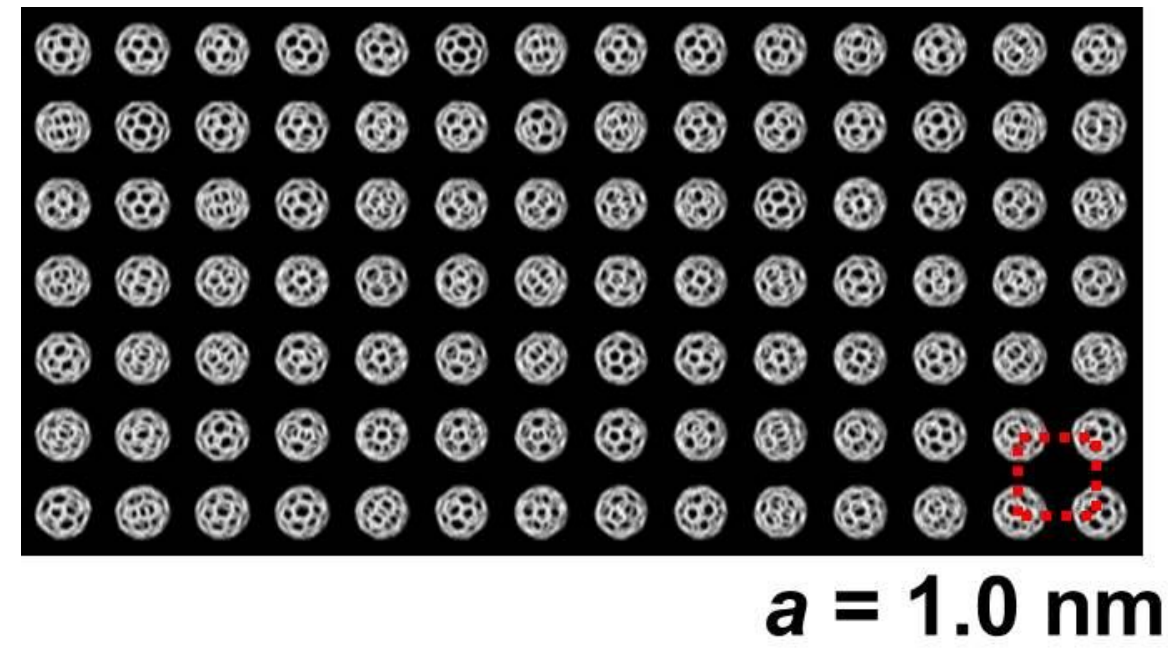

Figure S8. Molecular model showing the structure within the crystalline layer plane. A white skeleton frame, $0.7 \mathrm{~nm}$ in diameter, represents $\mathrm{C}_{60}$ without the surrounding $\pi$-electrons. The alkyl chains are omitted for clarity. 


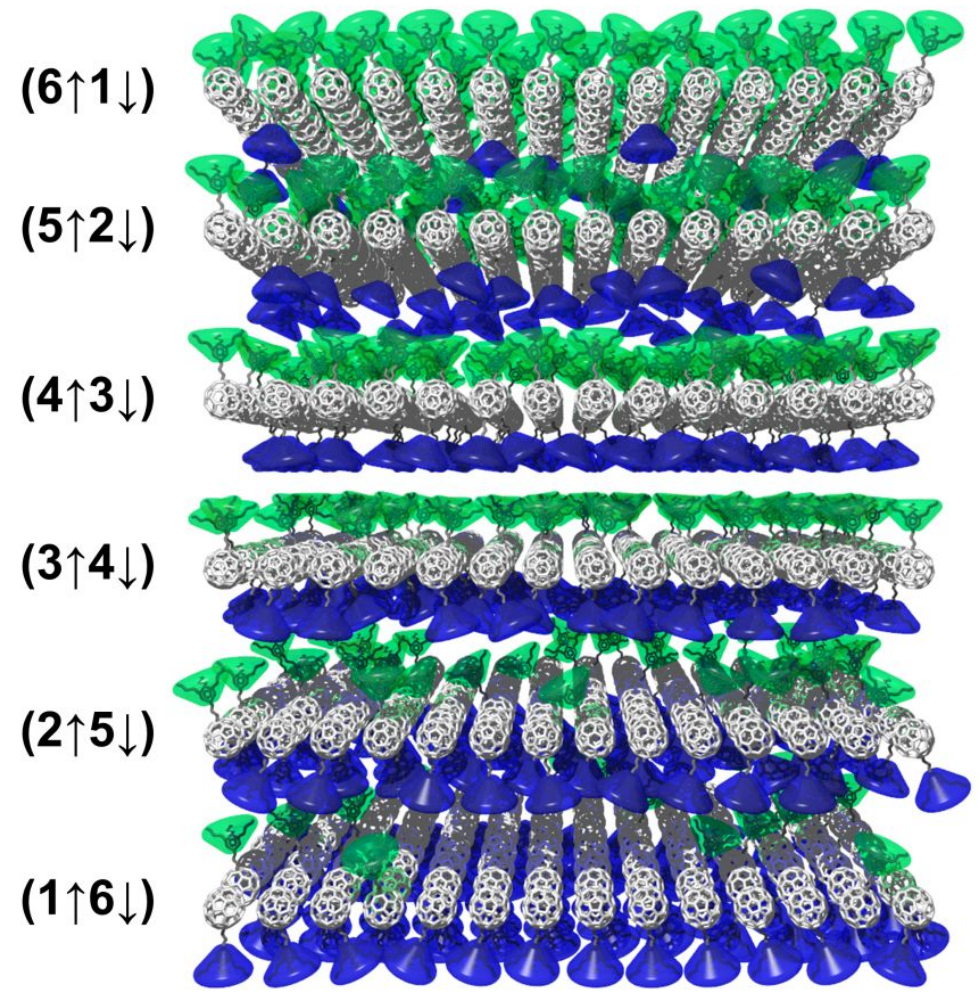

Figure S9. Perspective view of the successive sublayers from $6 \uparrow 1 \downarrow$ to $1 \uparrow 6 \downarrow$ in one superlattice period starting with most cones pointing down (blue) and ending with most cones pointing up (green). For a clearer view of each individual sublayer, the sublayers were shifted along the layer normal.
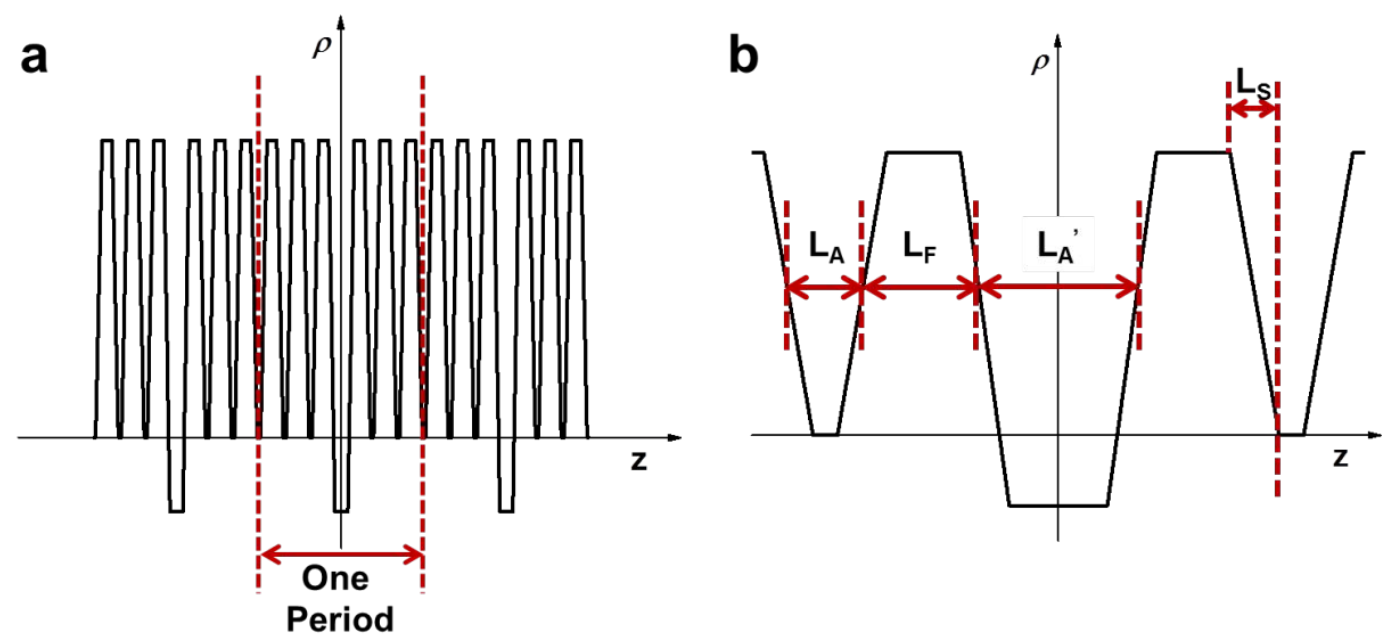

Figure S10. (a) Trapezoidal model electron density profiles normal to layer planes in the SL phase; (b) zoom-in image of (a). 


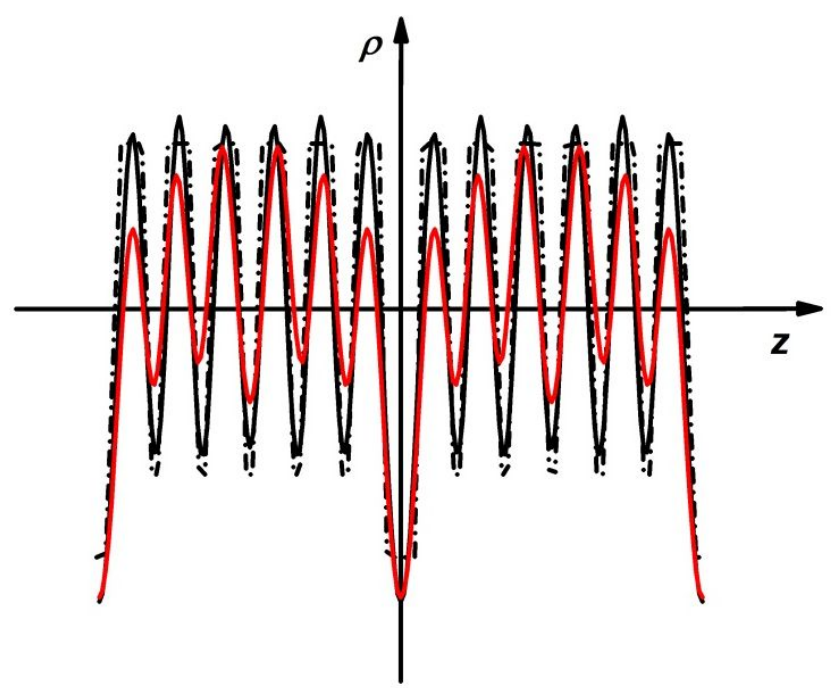

Figure S11. Model electron density profile normal to layer planes $\rho^{\text {trap }}(z)$ (dotted line); Electron density profile reconstructed from the fitting model $\rho^{F}(z)$ (black line) and the experimental data $\rho(z)$ (red line).

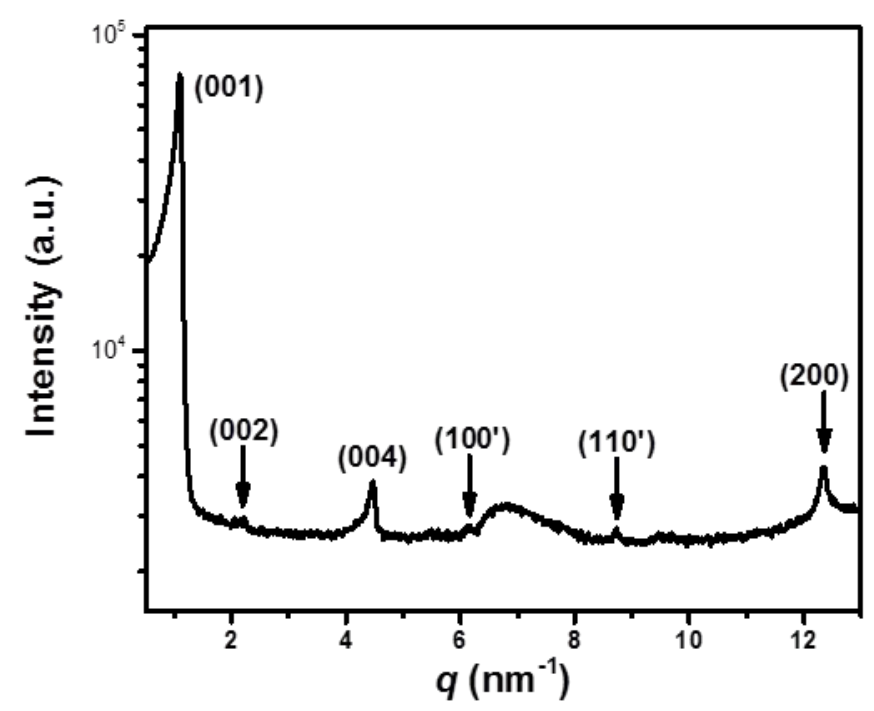

Figure S12. SAXS patterns of $\mathrm{C}_{7}-\mathrm{C}_{8}-\mathrm{C}_{60}$ at the high-temperature LQ phase $\left(144^{\circ} \mathrm{C}\right)$. 


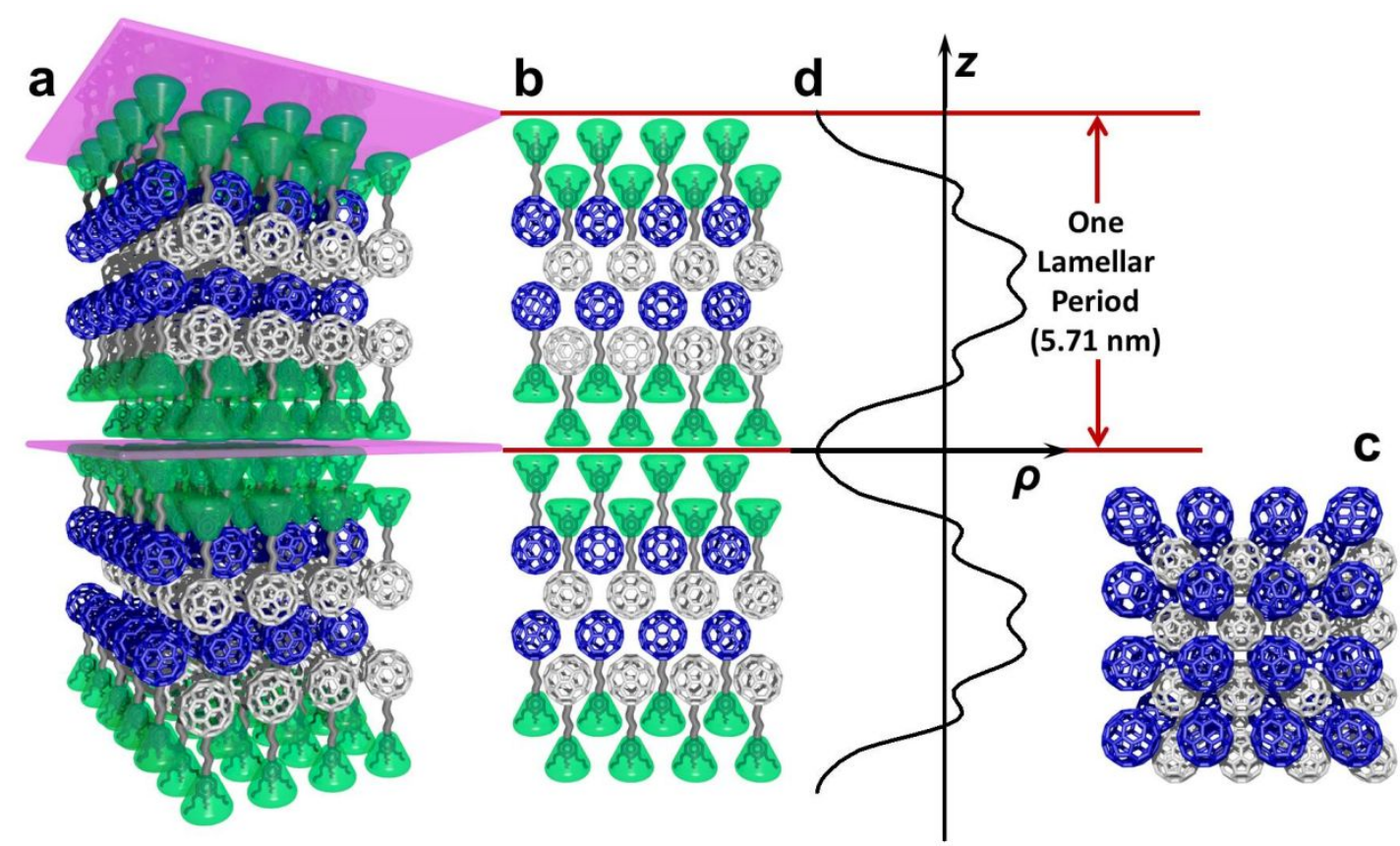

Figure S13. Representation of molecular packing of $\mathrm{C}_{7}-\mathrm{C}_{8}-\mathrm{C}_{60}$ in the LQ phase. (a) Side view, (b) front view and (c) top view of the molecular packing model. (d) Matching electron density profile $\rho(z)$ reconstructed from experimental diffraction intensities of the LQ phase obtained from Figure S12. For a clearer view of the model, the $\mathrm{C}_{60} \mathrm{~s}$ among $1^{\text {st }}$ and $3^{\text {rd }}$ layers are drawn in white, while those in $2^{\text {nd }}$ and $4^{\text {th }}$ layers are blue. The amorphous groups are omitted in (c) for better clarity.

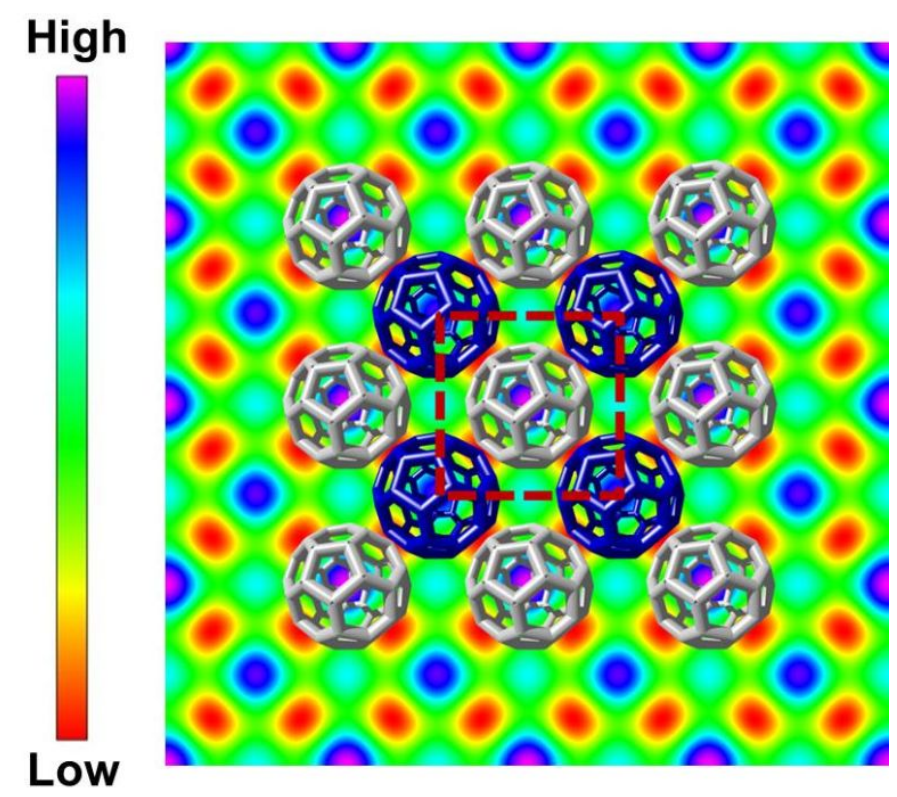

Figure S14. Electron density map of the LQ phase projected onto the layer plane. One square unit cell is marked by the red dash line. The fullerene-occupied high-density regions are in the middle and four corners of the unit cell. The white $\mathrm{C}_{60} \mathrm{~s}$ stand for the $\mathrm{C}_{60} \mathrm{~S}$ in the $1^{\text {st }}$ and $3^{\text {rd }}$ layers. The blue $\mathrm{C}_{60} \mathrm{~s}$ stand for the $\mathrm{C}_{60} \mathrm{~S}$ in the $2^{\text {nd }}$ and $4^{\text {th }}$ layers. 


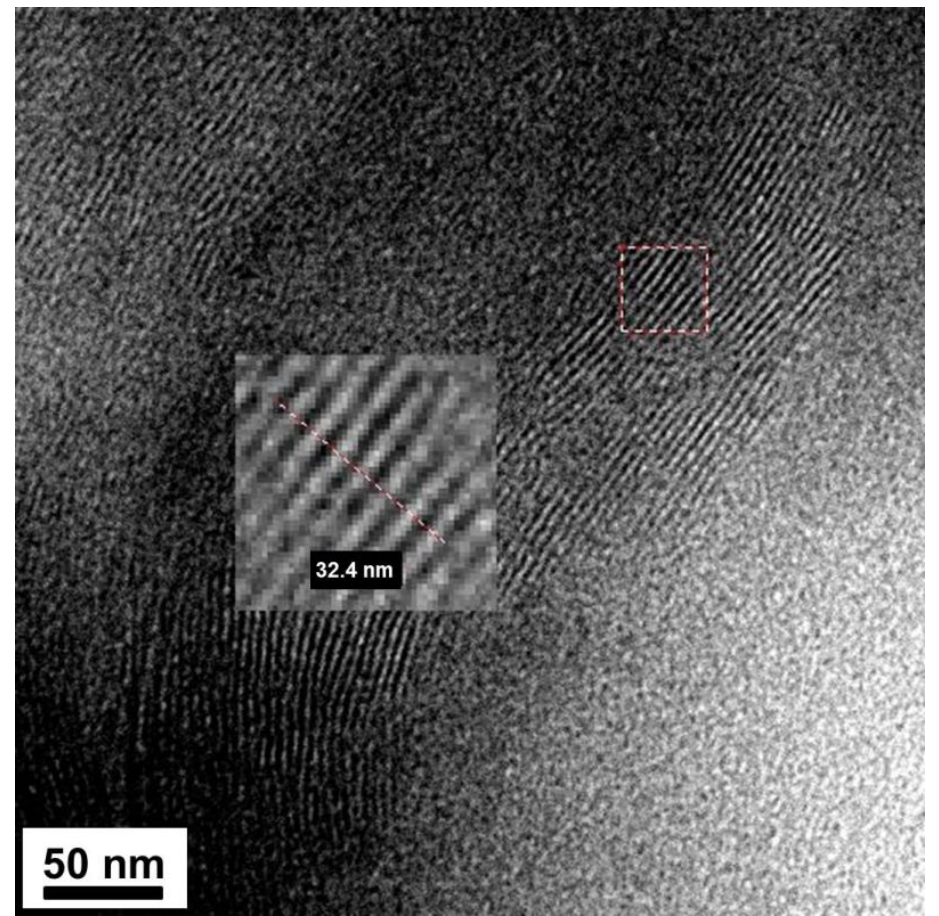

Figure S15. TEM image of $\mathrm{C}_{7}-\mathrm{C}_{8}-\mathrm{C}_{60}$ annealed at $150{ }^{\circ} \mathrm{C}$.

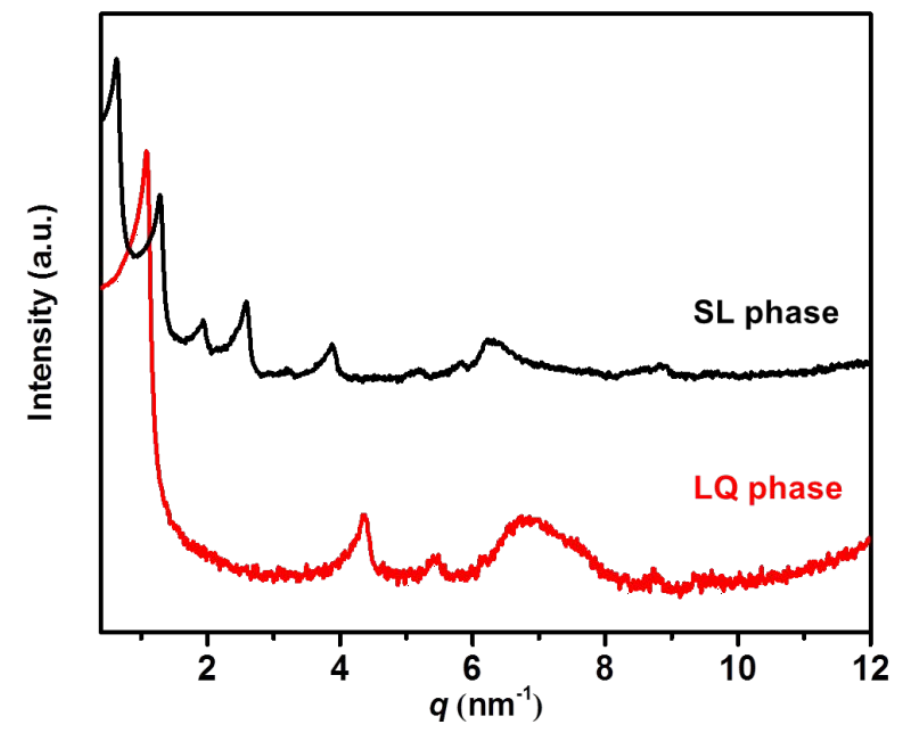

Figure S16. SAXS diffractograms of $\mathrm{C}_{7}-\mathrm{C}_{8}-\mathrm{C}_{60}$ film in the LQ phase by cooling the sample from isotropic melt to room temperature (red line), and in the SL phase by annealing the sample for 2 weeks (black line), similar to the test conditions of the TRMC measurement. In order to exhibit the weak peaks clearly, the intensities were shown on a logarithmic scale. 


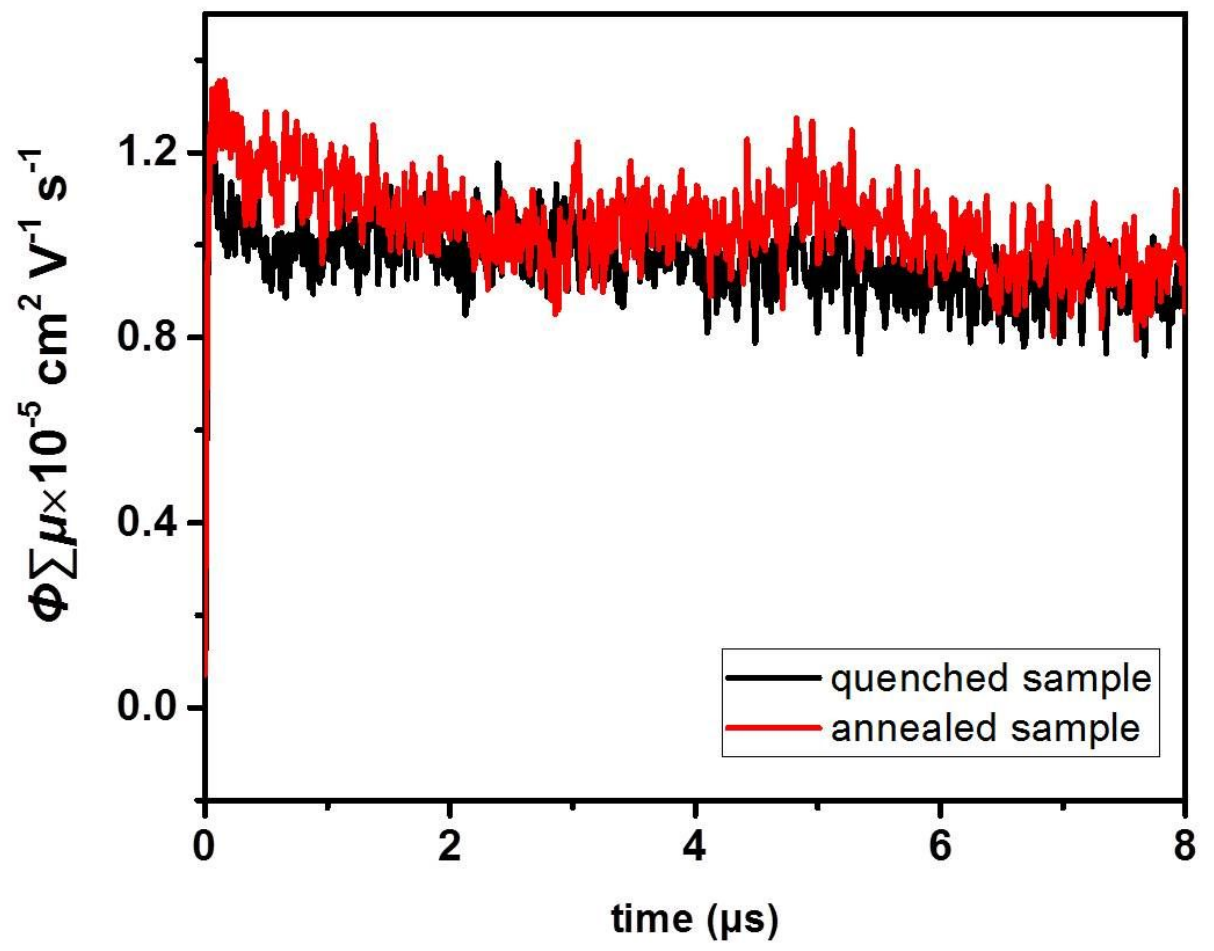

Figure S17. Conductivity transients at $0-8 \mu$ s of thin films of $\mathrm{C}_{14}-\mathrm{C}_{8}-\mathrm{C}_{60}$ quenched from isotropic to the triple-layer LC phase (black line) and annealed at R.T. for two weeks (red line). The photoexcitation wavelength and photon density were $355 \mathrm{~nm}$ and $9.1 \times 10^{15}$ photons $\mathrm{cm}^{-2}$ pulse ${ }^{-1}$, respectively.

\section{References}

(1) Tada, T.; Ishida, Y.; Saigo, K. Synthesis and reactions of 2,2[60]fullerenoalkanoyl chlorides. J. Org. Chem. 2006, 71, 1633-1639.

(2) Ma, B.; Bunker, C. E.; Guduru, R.; Zhang, X.-F.; Sun, Y.-P. Quantitative spectroscopic studies of the photoexcited state properties of methanoandpyrrolidino-[60]fullerene derivatives. J. Phys. Chem. A 1997, 101, 5626-5632.

(3) Huang, M.; Hsu, C.-H.; Wang, J.; Mei, S.; Dong, X.; Li, Y.; Li, M.; Liu, H.; Zhang, W.; Aida, T.; Zhang, W.-B.; Yue, K.; Cheng, S. Z. D. Selective assemblies of giant tetrahedra via precisely controlled positional interactions. Science 2015, 348, 424-428.

(4) Slater, J. C. Microwave electronics. Rev. Mod. Phys. 1946, 18, 441-512.

(5) Saeki, A.; Seki, S.; Sunagawa, T.; Ushida, K.; Tagawa, S. Charge-carrier dynamics in polythiophene films studied by in-situ measurement of flashphotolysis time-resolved microwave conductivity (FP-TRMC) and transient optical spectroscopy (TOS). Philos. Mag. 2006, 86, 1261-1276.

(6) Zhang, X.; Hsu, C.-H.; Ren, X.; Gu, Y.; Song, B.; Sun, H.-J.; Yang, S.; Chen, E.; Tu, Y.; Li, X.; Li, Y.; Zhu, X. Supramolecular [60]fullerene liquid crystals formed by self-organized two-dimensional crystals. Angew. Chem. Inter. Ed. 2015, 54, 114-117. 
(7) Shen, P.; Zhang, X.; Lu, H.; Su, Z.; Zhou, Y.; Song, B.; Li, X.; Yang, X.; Tu, Y.; $\mathrm{Li}, \mathrm{C}$. Y. Effect of fullerene volume fraction on two-dimensional crystalconstructed supramolecular liquid crystals. Chem. Asian J. 2019, 14, 125-129.

(8) Connolly, M. L. Solvent-accessible surfaces of proteins and nucleic acids. Science 1983, 221, 709-713.

(9) Connolly, M. L. Analytical molecular surface calculation. J. Appl. Cryst. 1983, 16, 548-558.

(10) Connolly, M. L. Computation of molecular volume. J. Am. Chem. Soc. 1985, 107, 1118-1124.

(11) Orwoll, R. A.; Flory, P. J. Equation-of-state parameters for normal alkanes. Correlation with chain length. J. Am. Chem. Soc. 1967, 89, 6814-6822.

(12) Yen, M.-H.; Chaiprapa, J.; Zeng, X.; Liu, Y.; Cseh, L.; Mehl, G. H.; Ungar, G. Added alkane allows thermal thinning of surpramolecular columns by forming superlattice-an X-ray and neutron study. J. Am. Chem. Soc. 2016, 138, 5757-5760. 